\title{
ЛИССАБОНСКИЙ ДОГОВОР: ФОРМИРОВАНИЕ КОМПЕТЕНЦИЙ ЕС В ОБЛАСТИ ОБЩЕЙ ВНЕШНЕЙ ПОЛИТИКИ И ПОЛИТИКИ БЕЗОПАСНОСТИ
}

\begin{abstract}
Аннотация. В статье анализируются изменения, внесенные в порядок формирования компетенций ЕС в области общей внешней политики и политики безопасности. Утверждается, что тендениией этих изменений является усиление полномочий институтов Союза. Исследуются особенности распределения компетенций между Союзом, Сообществами и государствами-членами ЕС в сфере общей внешней политики и политики безопасности.Автор утверждает, что в результате принятия и введения в действие Лиссабонского договора слияния между первой и второй «опорами» не произошло, поскольку в Европейском союзе, при всей его схожести с федеративныи образованием, нет политической интеграчии; поэтому сохраняется опасность подчинения внешнеэкономической политики общим внешнеполитическим интересам. Эти интересы формируются отдельными государствами и соответствующие решения не могут приниматься на наднациональном уровне. Фиксированных рамок понятия «общая внешняя политика и безопасность» не существует, и их определение, в соответствии с общим характером этой сферы деятельности, оставлено на усмотрение государств.
\end{abstract}

Ключевые слова: Европейский союз, общая внешняя политика, политика безопасности, компетенции ЕС, Лиссабонскийдоговор, Договор о функиионировании, Договор оС, государство, полномочия институтов Союза, суд. Abstract: The article contains analysis of the changes in the procedure of formation of the EU competences in the sphere of common foreign policy and security policy. It is stated that the tendency within these changes is for the strengthening of the competence of the EU institutions. The author studies the specific features of distribution of competences among the Union, the Communities and the EU Member States in the sphere of common foreign policy and security policy. The author states that as a result of adoption and implementation of the Lisbon Treaty there was not merging between the first and the second "pillars", since while the European Union is very similar to the federal structure, it has no political integration, that is why there is still a threat that the foreign economic policy shall be bound by common foreign political interests. These interests are formed by specific states, and such decisions cannot be made at the supranational level. There is no fixed framework for the "common foreign policy and security", and their definition according to the general character of this sphere of activities is left at the discretion of the states.

Keywords: the European Union, common foreign policy, security policy, competences of the EU, the Lisbon Treaty, the Treaty of the Functioning of the European Union, The EU Treaty, state, competences of the institutions of the Union, court.

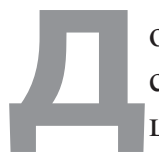

окумент, известный под названием «Лиссабонский договор», прекратил свое существование в момент вступления в силу изменений, внесенных им в основополагающие договоры Европейского союза.

Положениями Лиссабонского договора внесены изменения в три основополагающих документа Европейского союза:

- Договор об учреждении Европейского экономического сообщества (Римский договор), который теперь называется Договор о функционировании Европейского союза';

\footnotetext{
1 Текст с учетом изменений, внесенных Лиссабонским договором, см.:Treaty on the Functioning of the European Union// Official Journal C 83 of 30.3.2010
}

- Договор о Евратомегі;

- Договор об учреждении Европейского союза (Маастрихтский договор 1992 г. с изменениями, внесенными Амстердамским договором 1997г.) $)^{3}$.

После вступления Лиссабонского договора в силу, то есть после того, как стали действовать обновленные версии текстов учредительных документов, Лиссабонский договор как таковой перестал существовать.

Таким образом, в настоящее время нормативная основа Европейского союза состоит из

\footnotetext{
${ }^{2}$ Consolidated version of the Treaty establishing the European Atomic Energy Community//Official Journal C 84 of 30.3.2010.

${ }^{3}$ Consolidated version of the Treaty on European Union//Official Journal C 83 of 30.3.2010
} 
нескольких договоров, дополненных решениями Судов Союза (Суда Европейского союза и Суда первой инстанции), а также решениями институтов и органов Союза. Чтобы отличить эти обновленные версии договоров от тех, что существовали раньше, их стали называть «консолидированные», то есть «сводные», «вобравшие в себя обновления».

К числу действующих учредительных договоров относятся:

- Консолидированные версии Договора о Европейском союзе и Договора о функционировании Европейского союза

- Консолидированная версия Договора об учреждении Европейского сообщества по атомной энергии ${ }^{5}$;

- Хартия основных прав Европейского союза 6 .

Эти документы в совокупности составляют правовую основу нынешнего Европейского союза.

Лиссабонский договор содержит некоторые новации относительно ОВПБ, главным образом той же направленности, что в Конституционном договоре. Процедура взвешенного голосования сохранена и расширена. Сохранено и право «отклонения в случае чрезвычайных обстоятельств», которое позволяет государству не участвовать в объединенных действиях по жизненно важным соображениям. Действует и квалифицированное отклонение: какая-либо политическая линия Союза может быть отклонена, если за это проголосует одна треть государств-членов, население которых составляет одну треть Союза. Составители ЛД показали стремление усилить полномочия Высокого представителя по ОВПБ, который стал теперь именоваться Высоким представителем Союза по вопросам внешней политики и безопасности (ст.9е). Данное лицо выступает как вице-президент Комиссии «для обеспечения единообразия внешнеполитических действий Союза», так что он теперь соединяет функции Высокого представителя и Комиссара

\footnotetext{
${ }^{4}$ Consolidated versions of the Treaty on European Union and the Treaty on the Functioning of the European Union//Official Journal C 83 of 30.3 .2010

${ }^{5}$ Consolidated version of the Treaty establishing the European Atomic Energy Community//Official Journal C 84 of 30.3.2010

${ }^{6}$ Charter of Fundamental Rights of the European Union//Official Journal C 83 of 30.3 .2010
}

по внешним делам. Хотя Высокий представитель действительно сможет имплементировать лишь те решения, которые одобрены Советом, не следует недооценивать его полномочие выступать от имени 27 европейских стран.

Высокому представителю отведены и некоторые финансовые права. По ст.28 административные расходы, связанные с проведением ОВПБ, финансируются из бюджета Союза. Кроме того, Договором предусмотрено, что Совет обязан имплементировать процедуры для обеспечения быстрого доступа к союзному бюджету в случае необходимости провести срочное финансирование инициатив в рамках ОВПБ. Финансирование выполнения задач, не подпадающих под вышеназванную квалификацию, должно производиться из фонда взносов государств-членов по решению, принимаемому квалифицированным большинством, но не единогласно. В этом случае Совет уполномочивает Высокого представителя прибегнуть к авуарам фонда. Это значит, что такой фонд доступен Высокому представителю в целях исполнения общей воли Союза.

Тем не менее, Союзу не предоставлена полная власть на принятие внешнеполитических решений, и государства сохраняют значительную степень самостоятельности.

В большинстве случаев в сфере ОВПБ требуется единогласие. Ограничение числа решений, принимаемых квалифицированным голосованием, суживает сферу влияния Союза на ОВПБ.

Хотя Высокий представитель наделен полномочиями на имплементацию внешней политики, он подчиняется решениям Совета и обязан следовать им.

Таким образом, в течение более чем полувека, прошедших с начала первых попыток интеграции внешней политики в Европейском союзе, эта своеобразная организация прилагала множество усилий, чтобы найти свой собственный путь. От простых единичных шагов по координации внешней политики государств-членов ЕС двигался к целостной системе принятия решений. Высокий представитель, выступающий от лица всего Союза, - также уникальное должностное лицо в праве международных организаций.

Довольно быстрый темп образования новых структур, а также готовность государств к сближению их внешней политики - также новое явле- 
ние в международных отношениях. Мы пока не знаем, в каком направлении пойдет дальнейшее развитие ЕС в сфере управления внешней политикой. Но уже сейчас ясно, что Европейским союзом осуществлен большой прогресс, и в будущем это будет движение вперед, хотя и через трудности.

Изменения, внесенные Лиссабонским договором, не решили всех проблем, связанных с проведением внешней политики ЕС. Это объясняется объективными особенностями Союза: он не является государством, и не представляет собой «классическую» международную организацию. Поэтому распределение компетенций на принятие внешнеполитических решений и осуществление соответствующих действий - довольно сложная задача.

Принятием Лиссабонского договора формально ликвидирована «опорная» структура Союза. Те функции и полномочия, которые прежде принадлежали Сообществу, теперь осуществляет Союз. В ст.3 ДФЕС перечислены сферы исключительной компетенции Союза: таможенный союз; установление правил конкуренции, необходимых для функционирования внутреннего рынка; монетарная политика; сохранение морских биологических ресурсов; общая торговая политика.

Но что касается институтов и органов, то в их структуре кардинальных перемен не произошло. Лиссабонский договор практически никак не изменил полномочия институтов ЕС. Такие вопросы, как установление единого таможенного тарифа, правовое регулирование «свобод» общего рынка, отношения ЕС с Всемирной торговой организацией и следование установленным ею правилам - все это входит в исключительную компетенцию Комиссии и Совета. Их актам придано прямое действие, которое означает, что для вступления в силу им не нужна ратификация или иная форма признания со стороны государств - членов. Но принятие подобного акта в области внешних сношений может серьезно затронуть интересы государств, которые продолжают оставаться самостоятельными субъектами международного права.

Еще одна сложность порождается тем, что, стремясь к предотвращению узурпации власти, составители учредительным договоров ЕС специально предусмотрели, что ни один из четырех основных институтов (Совет, Комиссия, Европарламент, Суд) не может подменять другой либо представлять ЕС от имени всех институтов. Поэтому внутреннее право ЕС построено так, чтобы предотвратить чрезмерную концентрацию функций, а следовательно, и полномочий, в одном институте 7 . Однако функции не институционализированы, и их точное определение требует использования довольно сложных методов, как судебные решения, совместные действия, участие одних институтов в деятельности других и т.п. Это нередко приводит к некоторой двойственности, дублированию и конкуренции.

Все эти особенности делают процесс формирования внешнеполитических полномочий отдельных институтов весьма схожим с процессом формирования обычно-правовых норм в международном праве. То есть внутреннее право ЕС формируется не только таким способом, как в большинстве международных организаций: через решения своих органов или по соглашению между государствами-членами, но и более сложным путем повторяющихся действий какого-либо института и одобрения его Судом.

Хотя в Лиссабонском договоре сделана попытка более четко структурировать общую схему управления внешними делами, большая часть затруднений пока не устранена. В частности, полномочия в области внешних связей разделены между самим Евросоюзом и его государствами-участниками («по вертикали»), а также между полномочиями, принадлежавшими прежде Сообществу, с одной стороны, и полномочиями в области общей внешней политики и политики безопасности («по горизонтали»). Поэтому картина управления внешними связями получается очень мозаичной. Положениями Лиссабонского договора эта мозаичность не устранена, поскольку указанные выше полномочия распределялись между институтами и органами ЕC, которые остались практически неизменными.

В результате принятия и введения в действие Лиссабонского договора слияния между первой и второй "опорами» не произошло, поскольку в Европейском союзе, при всей его схожести с федеративным образованием, нет политической интеграции; поэтому сохраняется опасность

\footnotetext{
${ }^{7}$ См.: Топорнин Б.Н. Право и институты Европейских сообществ на современном этапе: основные понятия//Европейская интеграция: правовые проблемы. Книга первая. М., 1992. С.17.
} 
подчинения внешнеэкономической политики общим внешнеполитическим интересам. Эти интересы формируются отдельными государствами и соответствуюшие решения не могут приниматься на наднациональном уровне.

$\mathrm{B}$ рамках Общей внешней политики и политики безопасности (ОВПБ) компетенции до Лиссабонского договора распределялись в значительной степени по-другому, чем в Европейских сообществах. Глава V ДЕС не содержала подробных положений на этот счет. Ст.11 (п.1) просто наделяла Союз компетенцией «определять и имплементировать» ОВПБ «во всех сферах внешней политики и политики безопасности» для достижения перечисленных там же целей. Из этого можно сделать неверный вывод о том, что государствами Союзу были переданы все полномочия в области внешней политики, и что в рамки ОВПБ включены все внешние сношения. Но такой вывод противоречил бы простому факту: часть международных отношений Союза находилась в сфере компетенции Сообщества.

\section{1) Объем понятия «все сферы внешней политики и политики безопасности»}

Консолидированный текст ДЕС, в котором учтены изменения, внесенные Лиссабонским договором, содержит подобные же положения: в ст.24 компетенция Союза в области ОВПБ определяется как охватывающая все сферы внешней политики и все вопросы, относящиеся к безопасности Союза, в том числе определение рамок общей оборонной политики, вплоть до возможности общей обороны. Значит, перед нами стоит сложная задача - провести разграничительную линию: на горизонтальном уровне - между полномочиями Союза и бывшими институтами Сообщества; на вертикальном уровне - между полномочиями Союза и государств-членов.

С самого начала расширения сфер сотрудничества европейских стран шли поиски таких областей отношений, которые были бы жизненно важны для всех. Поскольку вплоть до начала 1990-х годов главными отношениями были экономические, в Программе Европейского политического сотрудничества, которая предшествовала созданию Европейского союза, в отличие от Маастрихтского договора, общей сферой и со- трудничества, и обеспечения безопасности, была названа экономика. Создатели ДЕС расширили понятие ОВПБ. Этому предшествовала попытка составить перечень критериев для определения важных общих интересов, чтобы не ограничиваться экономической сферой: Министрами иностранных дел был составлен доклад, которому не удалось придать обязательную юридическую силу ${ }^{8}$. Такими критериями для определения важных общих интересов в Докладе названы:

- географическая близость какого-либо региона или страны;

- заинтересованность в политической и экономической стабильности региона или страны;

- наличие угроз безопасности Союза.

Очевидно, что указанные критерии не отличаются конкретикой и точностью. Министрам не удалось создать более точные критерии, несмотря на все усилия. Видимо, и та неопределенность, которая характерна для регулирования ОВПБ, порождается невозможностью a priori обозначить те действия, которые могут оказаться необходимыми для определения и проведения общей внешней политики и политики безопасности.

Отсутствие четкой определенности в рамках ОВПБ оправдывается всей логикой построения $\mathrm{EC}:$ государства должны сохранять в своих руках контроль за объемом полномочий Союза9.

Важным вопросом является отделение общих полномочий на проведение внешней политики от полномочий в области обороны и безопасности. Если в число полномочий Союза включаются полномочия в области обороны, он становится оборонным союзом. В ст.42 КДЕС уточняется, что определение рамок общей оборонной политики Союза может привести к созданию общей обороны, если Европейский совет примет об этом единогласное решение. Последствиями такого решения будет рекомендации Европейского совета в адрес государств-членов признать его в

\footnotetext{
${ }^{8}$ Report to the European Council in Lisbon on the likely development of the Common Foreign and Security Policy (CFSP) with a view to identifying areas open to joint action vis-à-vis particular countries or groups of countries, adopted by the European Council at Lisbon on June 26th and 27th 1992, para 12.

${ }^{9}$ Dashwood A.A. Article 47 and the relationship between first and second pillar competences// Dashwood A.A. and Maresceau M. (eds). Law and Practice of EU External Relations: Salient Features of a Changing Landscape. 2008, p.232.
} 
соответствии с требованиями их конституций. Поэтому, утверждают авторы, исследовавшие данный вопрос, конечное решение останется за государствами, и потому не следует придавать большое юридическое значение фразе «поведет к созданию общей обороны», а понимать ее как чисто политическое заявление о намерения ${ }^{10}$.

Анализируя данную статью, И.Б.Горданов обращает внимание на то, что в сфере ОВПБ вопросы поддержания безопасности подлежат регулированию отнюдь не в том, что касается военного измерения, а прежде всего, его политических и экономических аспектов, и весьма условно в тех аспектах безопасности, которые имеют отношение к военным вопросам и вопросам обороны. По его мнению, аспекты безопасности далеко не случайно разделены на две сравнительно обособленные категории «общей оборонной политики» и «общей обороны». И.Б.Горданов считает, что эти две категории для своего дальнейшего развития потребуют применения специальных процедур. Он говорит: «В самом деле, в первом случае «общей оборонной политики», которая хотя и включена в текст договора о ЕС, однако для практического применения требует выработки специальных понятий, в частности, в том, что касается определенных оперативных вопросов ее реализации. В случае «общей обороны» Договор о ЕС содержит положение о ее возможном включении в будущем в текст договора о ЕС по единогласному решению Европейского совета и при поддержке этого решения всеми государствами-членами» ${ }^{11}$.

Действительно, ст.42 не накладывает на государства конкретно определенное обязательство создавать общую оборону. Союзу предоставляются полномочия на оперативные действия за его пределами в целях миротворчества, предотвращения конфликтов и укрепления международной безопасности в соответствии с принципами ООН. В ст.43 уточняется, что такие операции могут быть спасательными и гуманитарными, это может быть служба военных советников или совместные операции по разоружению.

Все эти задачи могут содействовать борьбе с терроризмом, в том числе через оказание поддержки третьим странам в борьбе с терроризмом

\footnotetext{
${ }^{10}$ Cremona M. The Draft Constitutional Treaty: External Relations and External Action. 2003, p.40.

${ }^{11}$ Горданов И.Б. Правовые основы внешнеполитической деятельности Европейского союза. Монография. М., 2009. С.109.
}

на их территориях. Есть мнение, что перечисление этих задач отразило уже существующую практику Союза, как, например, меры по предотвращению конфликтов и борьбе с терроризмом ${ }^{12}$.

Таким образом, фиксированных рамок понятия «общая внешняя политика и безопасность» не существует, и их определение, в соответствии с общим характером этой сферы деятельности, оставлено на усмотрение государств.

\section{2) Особенности распределения компетенций в области ОВПБ}

Из консолидированных текстов учредительных договоров следует, что Союз обладает разными категориями компетенций: исключительными, принадлежащими только ему, и разделяемыми с государствами. Согласно п.1 ст.4 ДФЕС Союз делит компетенции с государствами-членами в том случае, когда Договор наделяет его полномочиями, которые не затрагиваются положениями ст.3 и 6 (относительно его экономических и социальных функций, принадлежавших прежде Сообществам). Это значит, что лишь исключительные компетенции, а также полномочия Союза на совершение действий по поддержке, координации или дополнению действий государств-членов не попадают в категорию разделяемых компетенций. Методы осуществления компетенций в области ОВПБ можно рассматривать как относящиеся к разделяемым компетенциям между Союзом и государствами-членами. Декларации 13 и 14, приложенные к Заключительному акту по Лиссабонскому договору, ясно показывают, что его создатели намеренно не предоставили ОВПБ преимущественную силу ${ }^{13}$.

Если объем компетенции ЕС определяется его целями, означает ли это, что к данной сфере неприменим принцип делегирования государствами институтам Союза своих компетенций? Некоторые исследователи указывают, что, хотя в отношении Союза этот принцип прямо не предусмотрен, он все равно остается принципом данной между-

\footnotetext{
${ }^{12}$ Scannell D.L. Legal Aspects of the European Union's European Security and Defence Policy', PhD Dissertation (2005), p. 47 and 247.

13 Этими Декларациями предусмотрено, что ОВПБ (включая общую оборону и безопасность) не затрагивает существующей ныне ответственности государств-членов за формирование и проведение их внешней политики.
} 
DOI: $10.7256 / 2226-6305.2014 .2 .11588$

При цитировании этой статьи сноска на dоі обязательна

народной организации ${ }^{14}$. Более того, это один из принципов международных организаций вообще. Так было установлено еще в 20-х годах прошлого века в решении Постоянной палаты международного правосудия ${ }^{15}$ и обосновано в литературе ${ }^{16}$.

Поэтому, хотя внешнеполитические компетенции институтов ЕС в сфере ОВПБ не детализированы в учредительных документах, можно обоснованно утверждать, что эти компетенции определяются целями Союза в той степени, в какой любые действия в данной сфере вытекают из этих целей в соответствии с принципом делегирования. Однако получается, что в рамках ОВПБ распределение компетенций может быть иным, нежели это было установлено в рамках Сообщества, поскольку в Договоре о Сообществе были прямо приведены нормы, регулирующие такое распределение, а в ДЕС - нет. Эти различия дополняются тем, что для Сообществ, в отличие от Союза, внешнеполитические цели не были определены, и потому внимание исследователя невольно переносится на распределение компетенций ${ }^{17}$. Нельзя не признать, что с введением внешнеполитических целей для Союза в Маастрихтский договор эти же цели стали действовать и для сообществ, особенно в том, что касается сотрудничества в развитии. Цели как будто «перетекли» в положения, относящиеся к сообществам. Но нельзя сказать, что произошло взаимное движение, и что положения о распределении компетенций «перетекли» к Союзу.

Вторая особенность ОВПБ - в соответствующем разделе КДЕС ничего не говорится о подразумеваемых полномочиях. Но это не значит, что они не имеют места, поскольку они признаны общим международным правом применительно к международным организациям.

После принятия Лиссабонского договора важным дополнением ДФЕС стало положение о том, что при осуществлении гуманитарных операций меры, предпринимаемые Союзом и государствами-членами, должны дополнять и усиливать друг друга и проводиться в соответствии с принципами и целями внешнеполитической деятельности Союза и на основе принципов беспристрастности, нейтральности и недискриминации (ст.214 (2). То есть внутреннее право ЕС формируется не только таким способом, как в большинстве международных организаций: через решения своих органов или по соглашению между государствами-членами, но и более сложным путем повторяющихся действий какого-либо института и одобрения его Судом.

\section{Библиография:}

1. Топорнин Б.Н. Право и институты Европейских сообществ на современном этапе: основные понятия//Европейская интеграция: правовые проблемы. Книга первая. М., 1992. С.17.

2. Dashwood A.A. Article 47 and the relationship between first and second pillar competences// Dashwood A.A. and Maresceau M. (eds). Law and Practice of EU External Relations: Salient Features of a Changing Landscape. 2008, p.232.

3. Cremona M. The Draft Constitutional Treaty: External Relations and External Action. 2003, p.40.

\footnotetext{
${ }^{14}$ Например, см.: Gosalbo Bono R. Some Reflections on the CFSP Legal Order//European Law Review, 2006, p.358-359; в этом же смысле высказывались судьи Европейского суда: см. Opinion of Mengozzi AG in Case C-354/04 P Gestoras Pro Amnistía, J.M. Olano Olano, J. Zelarain Errastiv Council [2007] ECR I-1579 and Case C-355/04 P SEGI, A. Zubimendi Izaga, A. Galarraga v Council [2007] ECR I-1657, point 167.

${ }^{15}$ Jurisdiction of the European Commission of the Danube Between Galatz and Braila [1927] PCIJ Series B.- No 14, 64;

${ }^{16}$ Klabbers $J$. An Introduction to International Institutional Law (2002) 63-67. In general: D Sarooshi, International Organizations and Their Exercise of Sovereign Powers (2005).

${ }^{17}$ Cм.: Eeckhout P. External Relations of the European Union: Legal and Constitutional Foundations (2004) p. 138.
} 
4. Горданов И.Б. Правовые основы внешнеполитической деятельности Европейского союза. Монография. М., 2009. С.109.

5. Scannell D.L. Legal Aspects of the European Union's European Security and Defence Policy', PhD Dissertation (2005), p. 47 and 247.

6. Eeckhout P. External Relations of the European Union: Legal and Constitutional Foundations (2004) p. 138.

7. Фардеева И.Н. Роль субъектов Российской Федерации в приграничном сотрудничестве с Европейским Союзом. // NB: Международное право. - 2012. - № 1. - C.26-35. DOI: 10.7256/2306-9899.2012.1.496. URL: http://e-notabene.ru/wl/article_496.html

8. И. Г. Пашковская. Лиссабонский договор: регулирование деятельности Европейского Союза в энергетической сфере // Право и политика. - 2011. - № 8. - С. 104-107.

9. Постникова Е.В. Правовое регулирование признания профессиональных квалификаций в сфере предоставления услуг в Европейском Союзе // NB: Международное право. - 2013. - № 1. - С.75-122. DOI: 10.7256/2306-9899.2013.1.592. URL: http://e-notabene.ru/wl/article_592.html

10. Разумов Ю.А. Некоторые конституционно-правовоые особенности реализации норм международного права в военной сфере в зарубежных странах // NB: Международное право. - 2013. - № 1. C.171-183. DOI: 10.7256/2306-9899.2013.1.684. URL: http://e-notabene.ru/wl/article_684.html

11. Степаненко В.С. Источники европейского экологического права. // NB: Международное право. - 2013. - № 4. - C.161-183. DOI: 10.7256/2306-9899.2013.4.10072. URL: http://e-notabene.ru/wl/article_10072.html

12. Байректаревич A.. Future of Europe (of Lisbon and generational interval) // NB: Международные отношения. -2013. - № 4. - C.16-26. DOI: 10.7256/2306-4226.2013.4.9399. URL: http://e-notabene.ru/wi/article_9399.html

13. Киреева Н.В.. Понятие целостности в системной теории международной интеграции // Политика и Общество. - 2013. - № 11. - С. 104-107. DOI: 10.7256/1812-8696.2013.11.10200.

14. Цомая М.А.. Эволюция евразэс: политические амбиции или объективная реальность // Тренды и управление. - 2013. - № 3. - C. 104-107. DOI: 10.7256/2307-9118.2013.3.7582.

15. И. А. Холов. Евразийский Союз, проблемы и перспективы развития // Право и политика. - 2012. № 5. - С. 104-107

\section{References (transliteration):}

1. Topornin B.N. Pravo i instituty Evropeiskikh soobshchestv na sovremennom etape: osnovnye ponyatiya// Evropeiskaya integratsiya: pravovye problemy. Kniga pervaya. M., 1992. S.17.

2. Dashwood A.A. Article 47 and the relationship between first and second pillar competences// Dashwood A.A. and Maresceau M. (eds). Law and Practice of EU External Relations: Salient Features of a Changing Landscape. 2008, p.232.

3. Cremona M. The Draft Constitutional Treaty: External Relations and External Action. 2003, p.40.

4. Gordanov I.B. Pravovye osnovy vneshnepoliticheskoi deyatel'nosti Evropeiskogo soyuza. Monografiya. M., 2009. S.109.

5. Scannell D.L. Legal Aspects of the European Union's European Security and Defence Policy', PhD Dissertation (2005), r. 47 and 247.

6. Eeckhout P. External Relations of the European Union: Legal and Constitutional Foundations (2004) r. 138.

7. Fardeeva I.N. Rol' sub"'ektov Rossiiskoi Federatsii v prigranichnom sotrudnichestve s Evropeiskim Soyuzom. // NB: Mezhdunarodnoe pravo. - 2012. - № 1. - S.26-35. DOI: 10.7256/2306-9899.2012.1.496. URL: http://e-notabene.ru/wl/article_496.html

8. I. G. Pashkovskaya. Lissabonskii dogovor: regulirovanie deyatel'nosti Evropeiskogo Soyuza v energeticheskoi sfere // Pravo i politika. - 2011. - № 8. - S. 104-107.

9. Postnikova E.V. Pravovoe regulirovanie priznaniya professional'nykh kvalifikatsii v sfere predostavleniya uslug v Evropeiskom Soyuze // NB: Mezhdunarodnoe pravo. - 2013. - № 1. - S.75-122. DOI: 10.7256/23069899.2013.1.592. URL: http://e-notabene.ru/wl/article_592.html 
10. Razumov Yu.A. Nekotorye konstitutsionno-pravovoye osobennosti realizatsii norm mezhdunarodnogo prava v voennoi sfere v zarubezhnykh stranakh // NB: Mezhdunarodnoe pravo. - 2013. - № 1. - S.171-183. DOI: 10.7256/2306-9899.2013.1.684. URL: http://e-notabene.ru/wl/article_684.html

11. Stepanenko V.S. Istochniki evropeiskogo ekologicheskogo prava. // NB: Mezhdunarodnoe pravo. - 2013. № 4. - S.161-183. DOI: 10.7256/2306-9899.2013.4.10072. URL: http://e-notabene.ru/wl/article_10072.html

12. Bairektarevich A.. Future of Europe (of Lisbon and generational interval) // NB: Mezhdunarodnye otnosheniya. - 2013. - № 4. - S.16-26. DOI: 10.7256/2306-4226.2013.4.9399. URL: http://e-notabene.ru/wi/ article_9399.html

13. Kireeva N.V.. Ponyatie tselostnosti v sistemnoi teorii mezhdunarodnoi integratsii // Politika i Obshchestvo. - 2013. - № 11. - S. 104-107. DOI: 10.7256/1812-8696.2013.11.10200.

14. Tsomaya M.A.. Evolyutsiya evrazes: politicheskie ambitsii ili ob"ektivnaya real'nost' // Trendy i upravlenie. - 2013. - № 3. - S. 104-107. DOI: 10.7256/2307-9118.2013.3.7582.

15. I. A. Kholov. Evraziiskii Soyuz, problemy i perspektivy razvitiya // Pravo i politika. - 2012. - № 5. - S. 104-107 